\title{
Bis(m-phenylene)-32-Crown-10-Based Cryptands, Powerful Hosts for Paraquat Derivatives
}

Feihe Huang, ${ }^{\curlyvee}$ Karen A. Switek, ${ }^{\curlyvee \dagger}$ Lev N. Zakharov, ${ }^{\dagger, \Omega}$ Frank R. Fronczek, ${ }^{\$}$ Carla Slebodnick, ${ }^{\circ}$ Matthew Lam, ${ }^{\ddagger}$ James A. Golen, ${ }^{\oplus}$ William S. Bryant, ${ }^{, £}$ Philip E. Mason, ${ }^{\vee}, \Psi$ Arnold L. Rheingold, ${ }^{\ddagger, \Omega}$ Mehdi Ashraf-Khorassani, ${ }^{\vee}$ and Harry W. Gibson ${ }^{\vee, *}$

${ }^{-}$Department of Chemistry, Virginia Polytechnic Institute \& State University, Blacksburg, VA, 24061; Email: hwgibson@vt.edu; FAX: 540-231-8517. ' Summer Undergraduate Research Participant, 1999, supported by the National Science Foundation through DMR 922487 REU. Present address: Department of Chemistry, University of Minnesota, Minneapolis, MN 554550431. ${ }^{*}$ Department of Chemistry and Biochemistry, University of Delaware, Newark, Delaware 19716. ${ }^{\Omega}$ Present address: Department of Chemistry and Biochemistry, University of California, San Diego, La Jolla, CA, 92093-0358. \$ Department of Chemistry, Louisiana State University, Baton Rouge, LA, USA 70803. ${ }^{\epsilon}$ Department of Chemistry and Biochemistry, University of Massachusetts Dartmouth, North Dartmouth, MA, 02747. ${ }^{\ddagger}$ Present address: Imerys Pigments, INC., Roswell, GA, 30076. ${ }^{\Psi}$ Present address: Department of Food Science, Cornell University, Ithaca, NY 14853.

\section{Supplemental Material (10 pages)}

1. The preliminary crystal structure of $\mathbf{3 e} \bullet \mathbf{2 a} \quad \mathrm{S} 2$

2. Electrospray mass spectrum of a solution of $3 \boldsymbol{b}$ and $2 \boldsymbol{a}$ in methanol S3

3. Electrospray mass spectrum of a solution of $3 \boldsymbol{c}$ and $2 \boldsymbol{a}$ in methanol S4

4. Electrospray mass spectrum of a solution of $3 \boldsymbol{d}$ and $2 \boldsymbol{a}$ in methanol S5

5. Electrospray mass spectrum of a solution of $\mathbf{3 e}$ and $\mathbf{2 a}$ in a mixture of acetonitrile and chloroform (4:1)

6. ORTEP diagrams of the X-ray crystal structures of $\mathbf{2 a}$ with $50 \%$ probability ellipsoids

7. ORTEP diagrams of the X-ray crystal structures of $3 \boldsymbol{b}$ with $50 \%$ probability ellipsoids

8. ORTEP diagrams of the X-ray crystal structures of $3 \boldsymbol{e}$ with $50 \%$ probability ellipsoids

9. Proton NMR Spectrum $\left(400 \mathrm{MHz}, \mathrm{CDCl}_{3}, 22^{\circ} \mathrm{C}\right)$ of $\mathbf{3 b}$

10. Proton NMR Spectrum $\left(400 \mathrm{MHz}, \mathrm{CDCl}_{3}, 22^{\circ} \mathrm{C}\right)$ of $3 \mathrm{c}$

S9

11. Proton NMR Spectrum $\left(400 \mathrm{MHz}, \mathrm{CDCl}_{3}, 22^{\circ} \mathrm{C}\right)$ of $3 \boldsymbol{d}$

S9

12. Proton NMR Spectrum $\left(400 \mathrm{MHz}, \mathrm{CDCl}_{3}, 22^{\circ} \mathrm{C}\right)$ of $3 \boldsymbol{e}$ 


\section{The preliminary crystal structure of $3 \boldsymbol{e} \bullet \mathbf{2 a}$}

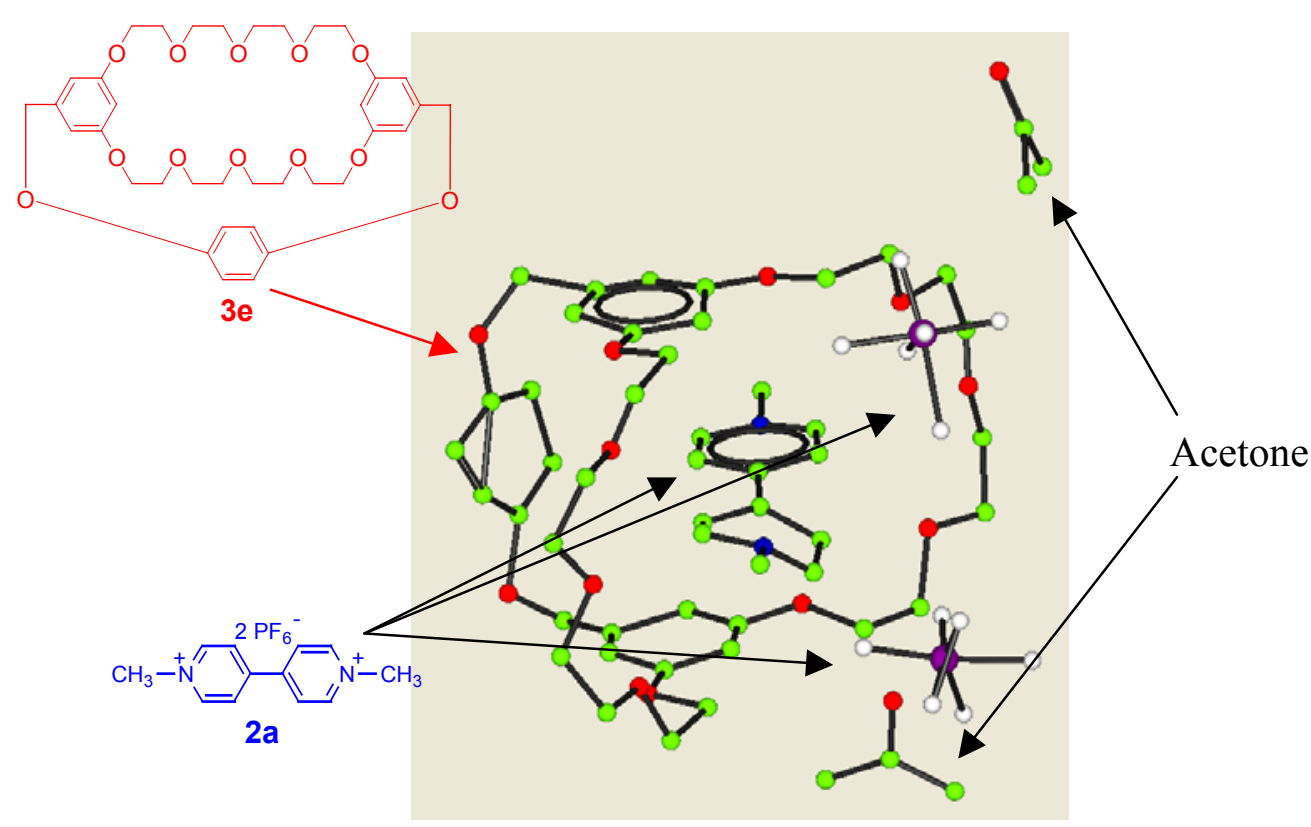

Bright yellow crystals of $\mathbf{3 e \bullet 2 a}$ were grown by vapor diffusion of pentane into an acetone solution of $2 \mathrm{a}$ with excess $3 \mathrm{e}$. The structure was solved by the direct method $\mathrm{SIR}^{\mathrm{S} 1}$ in Crystals. ${ }^{\mathrm{S} 2}$ Data were collected in a range $1.06^{\circ} \leq \theta \leq 27.50^{\circ}$ on an Oxford Diffraction XCalibur2 $2^{\mathrm{TM}}$ diffractometer equipped with the Enhance X-ray Source ${ }^{\mathrm{TM}}$ (MoK $\alpha$ radiation; $\lambda=0.71073 \AA$ ) and a Sapphire $2^{\mathrm{TM}}$ CCD detector by the phi and omega scan method.

S1. Altomare, A.; Cascarano, G.; Giacovazzo, C.; Guagliardi, A. J. Appl. Cryst. 1993, 26, 343-350.

S2. Watkin, D. J.; Prout, C. K.; Carruthers, J. R.; Betteridge, P. W.; Cooper, R. I. CRYSTALS 2000, Issue 11. Chemical Crystallography Laboratory, University of Oxford, Oxford. 


\section{Electrospray mass spectrum of a solution of $\mathbf{3} \boldsymbol{b}$ and $\mathbf{2} \boldsymbol{a}$ in methanol}

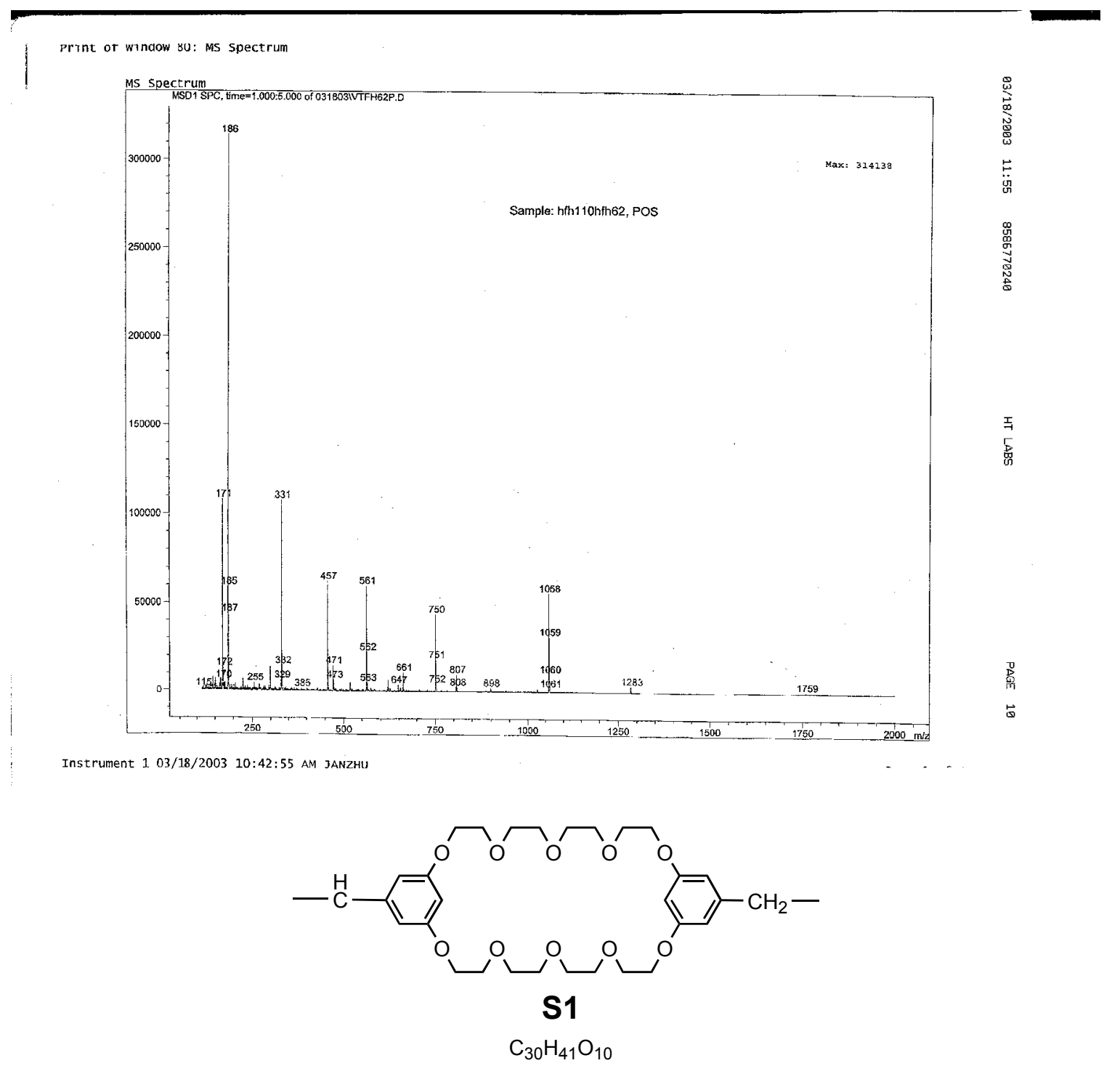

Assignments of main peaks: $m / z 1058\left[\mathbf{3 b} \cdot \mathbf{2} \mathbf{a}-\mathrm{PF}_{6}\right]^{+}, 898\left[\mathbf{3 b} \cdot \mathbf{2} \mathbf{a}-2 \mathrm{PF}_{6}-\mathrm{CH}_{3}\right]^{+}, 807\left[\mathbf{2} \mathbf{a}_{2}-\mathrm{PF}_{6}\right]^{+}$, $750[\mathbf{3 b}+\mathrm{Na}]^{+}, 561[\mathbf{S 1}]^{+}, 457\left[\mathbf{3 b} \cdot \mathbf{2 a}-2 \mathrm{PF}_{6}\right]^{2+}, 331\left[\mathbf{2 a}-\mathrm{PF}_{6}\right]^{+}, 186\left[\mathbf{2 a}-2 \mathrm{PF}_{6}\right]^{+}$, and $171[\mathbf{2 a}-$ $\left.2 \mathrm{PF}_{6}-\mathrm{CH}_{3}\right]^{+}$. 


\section{Electrospray mass spectrum of a solution of $3 c$ and $2 a$ in methanol}

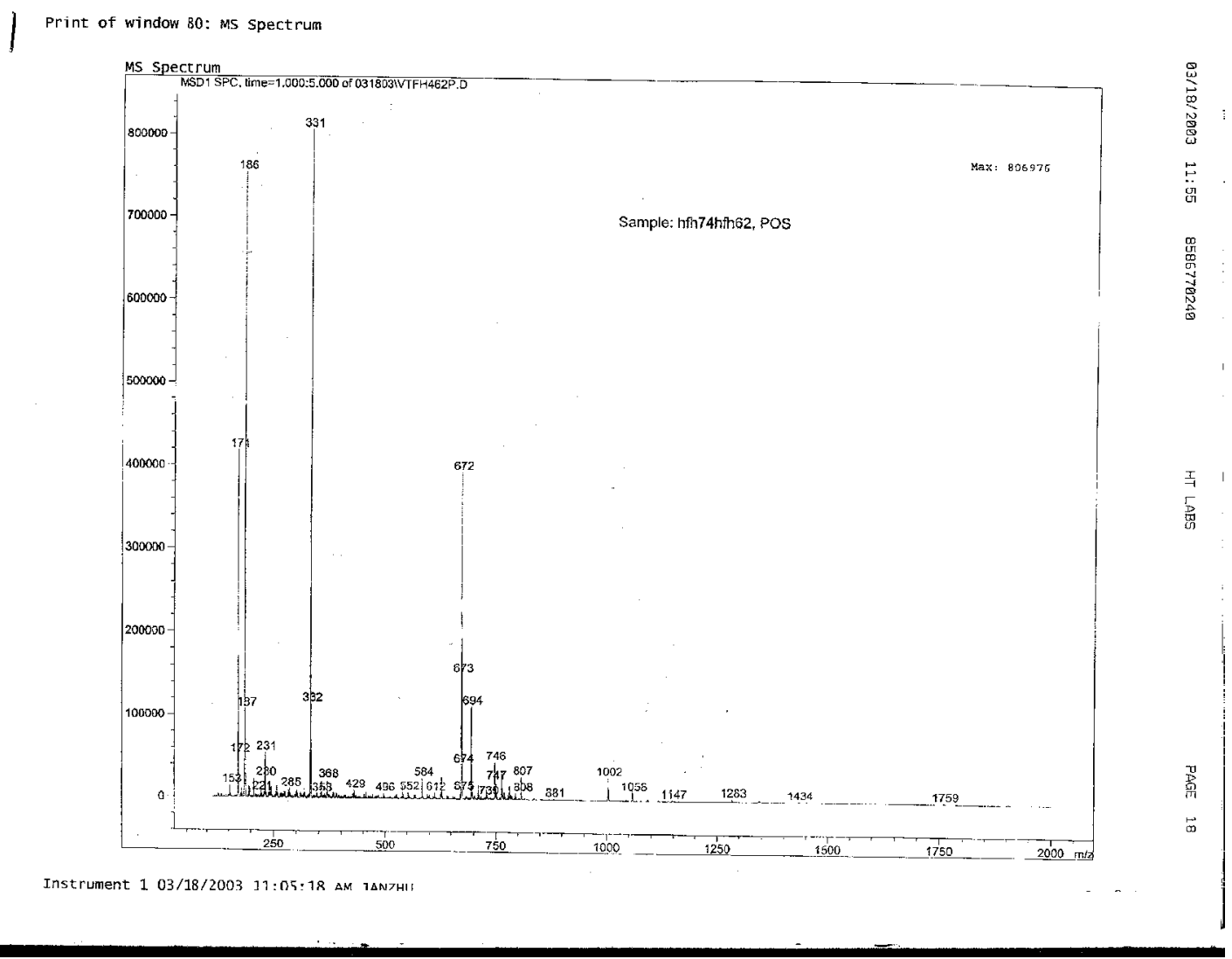

Assignments of main peaks: $m / z 1147[\mathbf{3 c} \cdot \mathbf{2 a}]^{+}, 1058\left[\mathbf{3} \mathbf{c} \cdot \mathbf{2 a}-\mathrm{HPF}_{6}+\mathrm{K}+\mathrm{H}_{2} \mathrm{O}\right]^{+}, 1002[\mathbf{3 c} \cdot \mathbf{2 a}-$ $\left.\mathrm{PF}_{6}\right]^{+}, 807\left[\mathbf{2} \mathbf{a}_{2}-\mathrm{PF}_{6}\right]^{+}, 694[\mathbf{3 c}+\mathrm{Na}]^{+}, 672[\mathbf{3 c}+\mathrm{H}]^{+}, 429\left[\mathbf{3 c} \cdot \mathbf{2 a}-2 \mathrm{PF}_{6}\right]^{2+}, 331\left[\mathbf{2 a}-\mathrm{PF}_{6}\right]^{+}, 186$ $\left[\mathbf{2 a}-2 \mathrm{PF}_{6}\right]^{+}$, and $171\left[\mathbf{2 a}-2 \mathrm{PF}_{6}-\mathrm{CH}_{3}\right]^{+}$. 


\section{Electrospray mass spectrum of a solution of $3 \boldsymbol{d}$ and $2 \boldsymbol{a}$ in methanol}

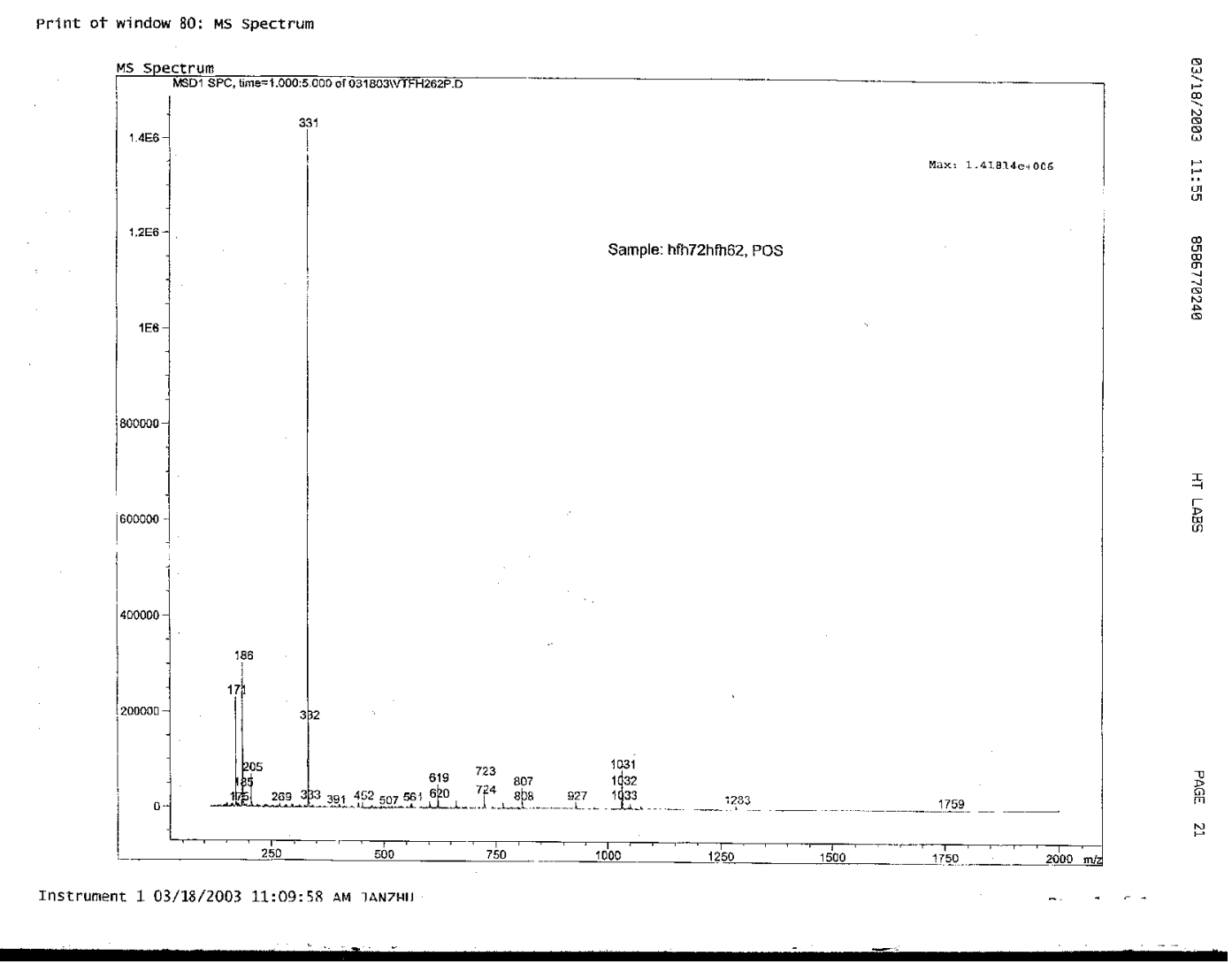

Assignments of main peaks: $m / z 1031\left[\mathbf{3 d} \cdot \mathbf{2} \mathbf{a}-\mathrm{PF}_{6}\right]^{+}, 927\left[\mathbf{3 d} \cdot \mathbf{2} \mathbf{a}-2 \mathrm{PF}_{6}+\mathrm{K}\right]^{+}, 807\left[\mathbf{2} \mathbf{a}_{2}-\mathrm{PF}_{6}\right]^{+}$, $723[\mathbf{3 d}+\mathrm{Na}]^{+}, 619\left[\mathbf{S 1}+\mathrm{K}+\mathrm{H}_{2} \mathrm{O}\right]^{+}, 561[\mathbf{S 1}]^{+}, 452\left[\mathbf{3 d \bullet 2 a}-2 \mathrm{PF}_{6}+\mathrm{H}_{2} \mathrm{O}\right]^{2+}, 331\left[\mathbf{2 a}-\mathrm{PF}_{6}\right]^{+}$, $186\left[\mathbf{2 a}-2 \mathrm{PF}_{6}\right]^{+}$, and $171\left[\mathbf{2 a}-2 \mathrm{PF}_{6}-\mathrm{CH}_{3}\right]^{+}$. 
5. Electrospray mass spectrum of a solution of $\mathbf{3 e}$ and $\mathbf{2} \boldsymbol{a}$ in a mixture of acetonitrile and chloroform (4:1)

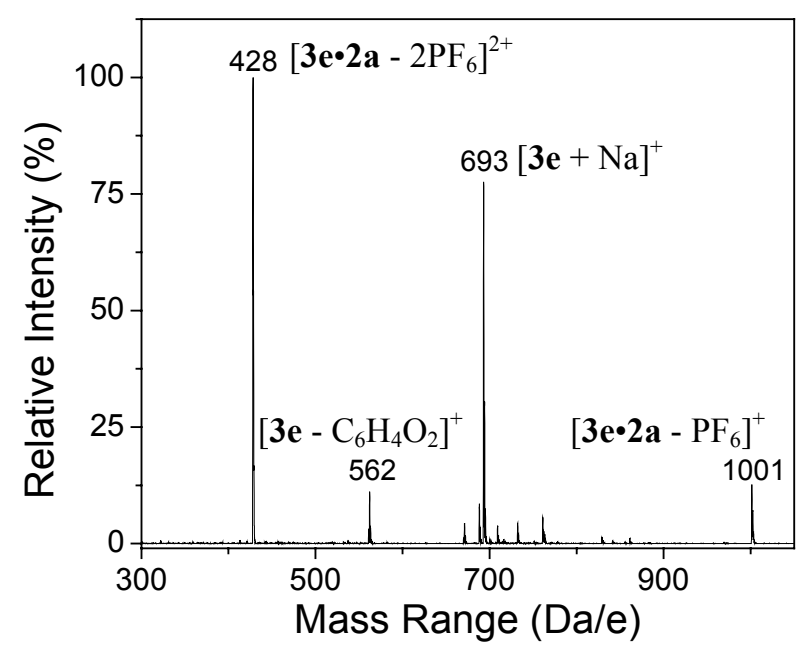

6. ORTEP diagrams of the X-ray crystal structures of $\mathbf{2 a}$ with $50 \%$ probability ellipsoids
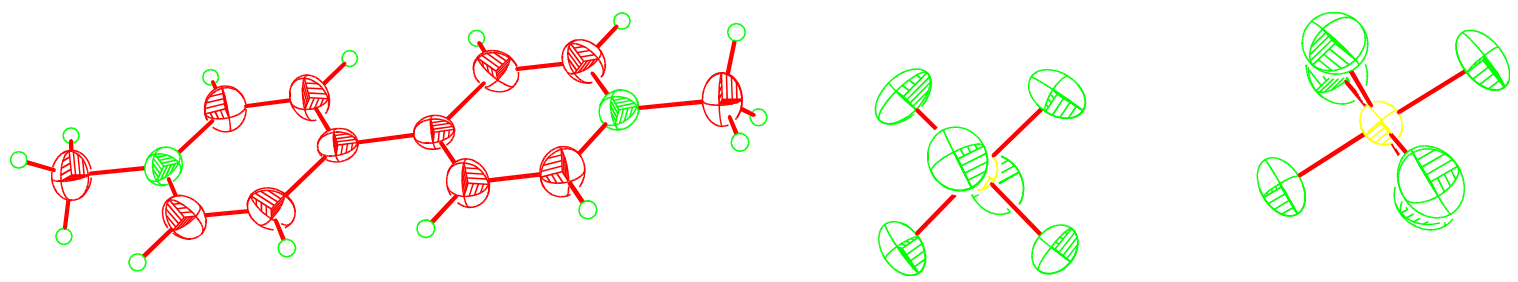
7. ORTEP diagrams of the X-ray crystal structures of $3 \boldsymbol{b}$ with $50 \%$ probability ellipsoids

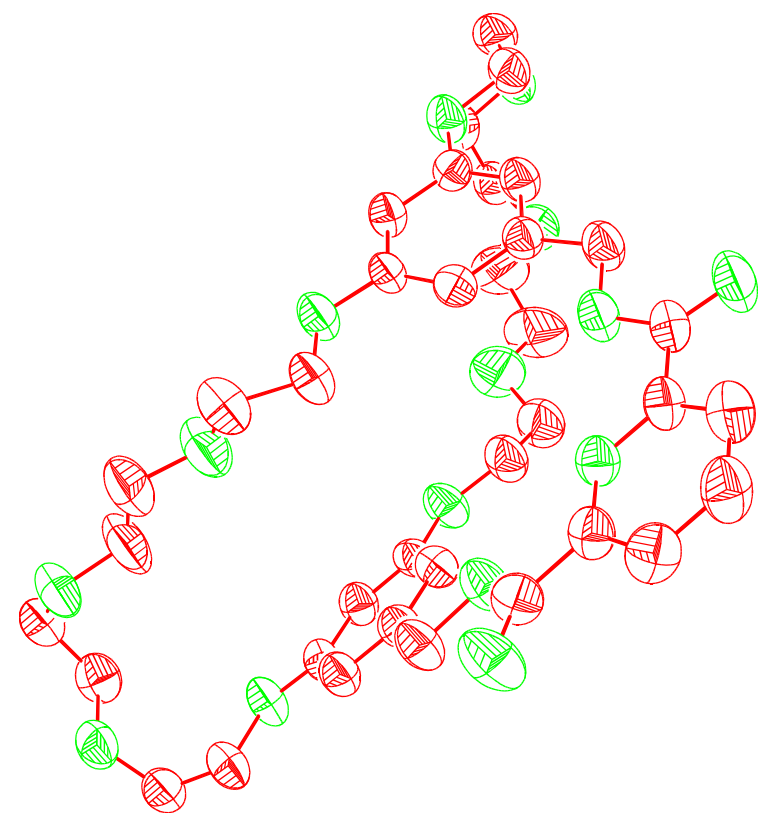

8. ORTEP diagrams of the X-ray crystal structures of $3 \mathrm{e}$ with $50 \%$ probability ellipsoids

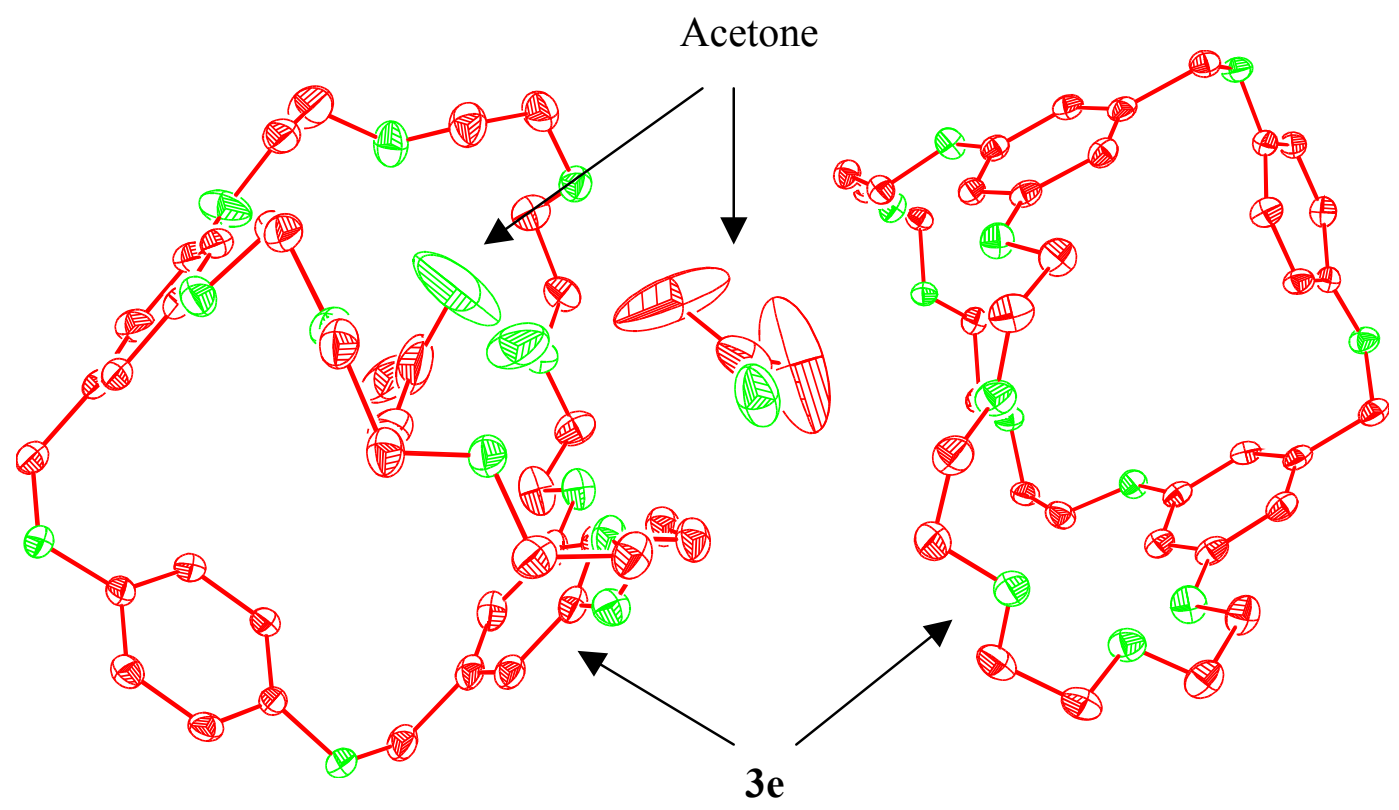


9. Proton NMR Spectrum (400 MHz, $\mathrm{CDCl}_{3}, 22^{\circ} \mathrm{C}$ ) of $\mathbf{3 b}$

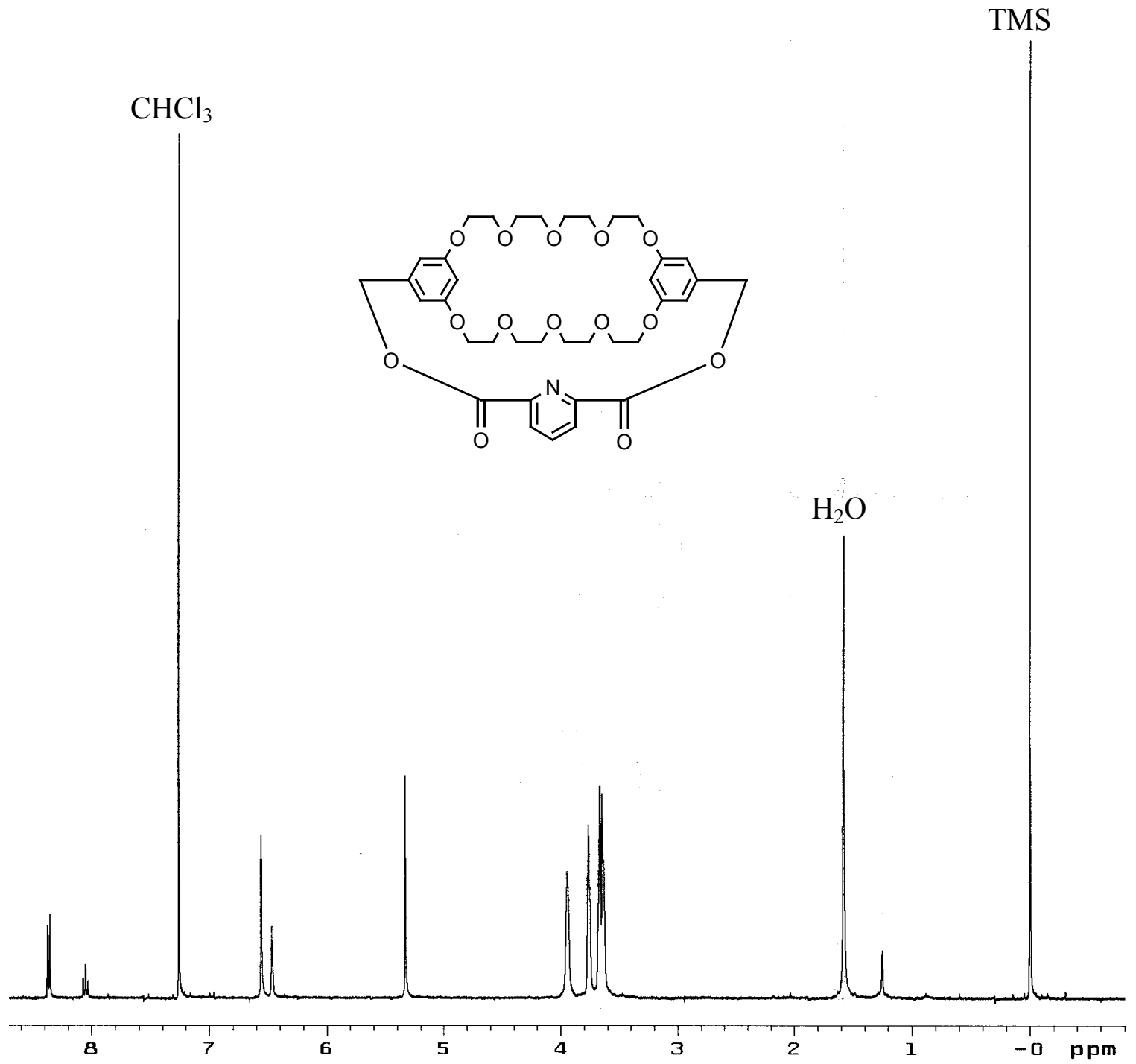


10. Proton NMR Spectrum (400 MHz, CDCl $\left.3,22{ }^{\circ} \mathrm{C}\right)$ of $3 \mathrm{c}$

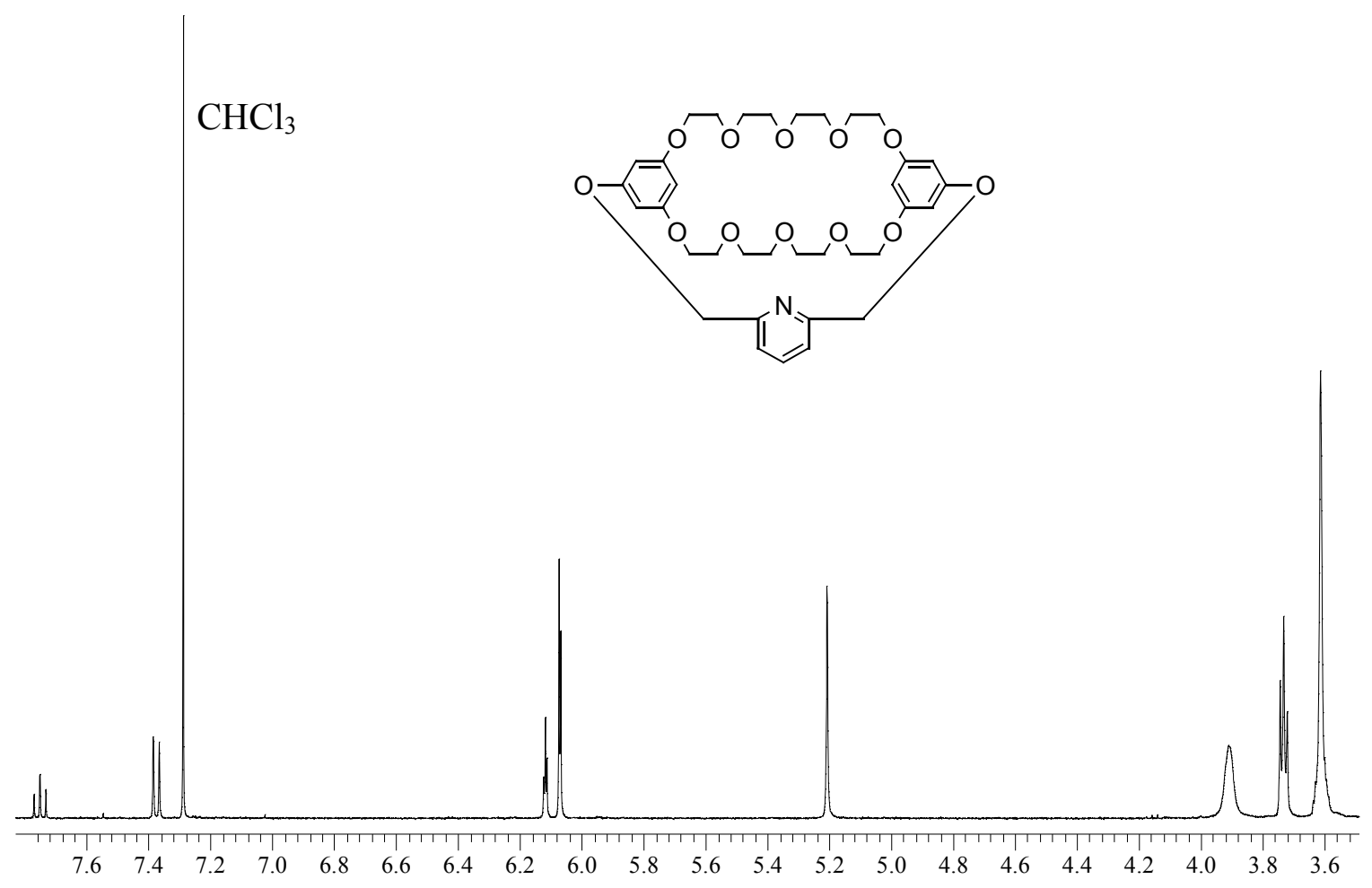

11. Proton NMR Spectrum (400 MHz, CDCl $3,22{ }^{\circ} \mathrm{C}$ ) of $3 \boldsymbol{d}$

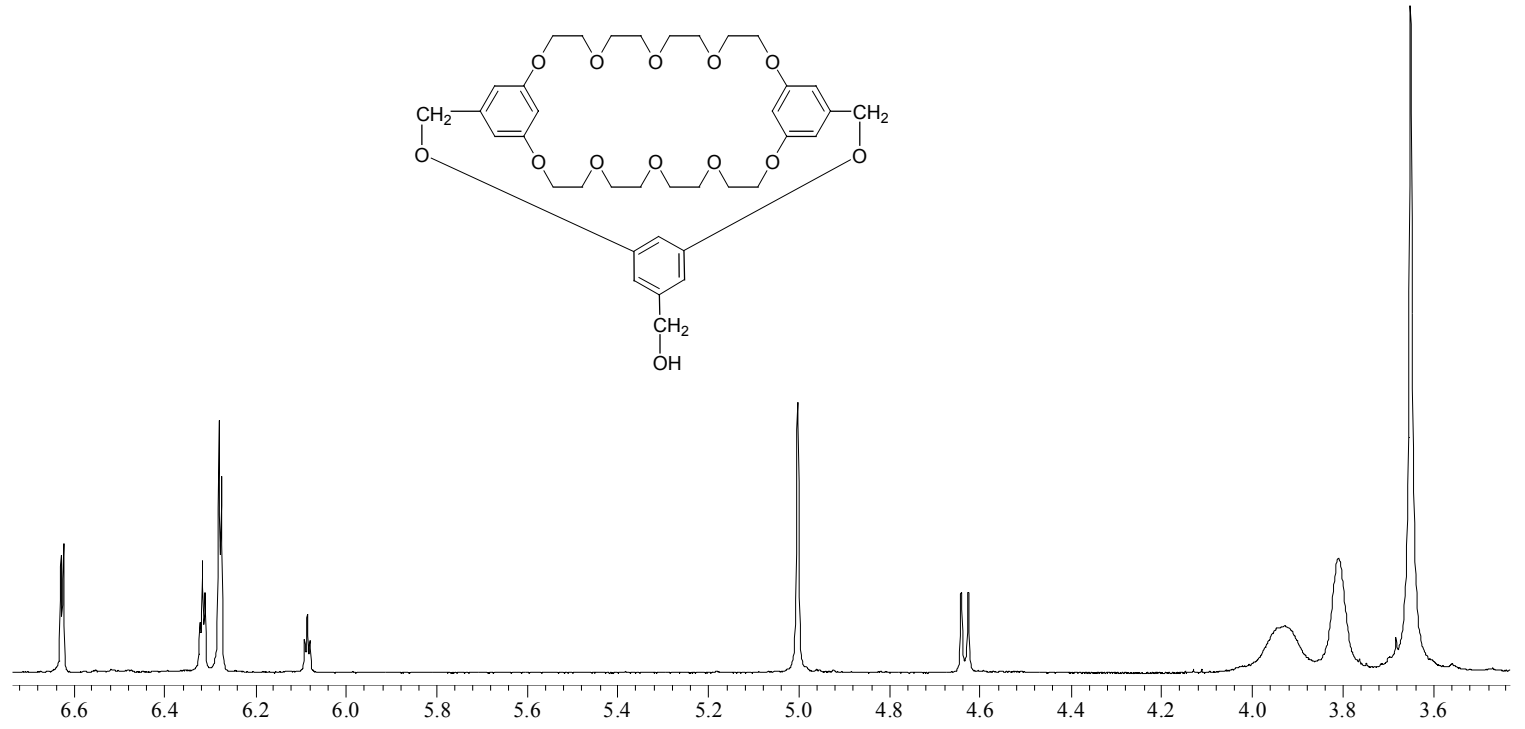


12. Proton NMR Spectrum $\left(400 \mathrm{MHz}, \mathrm{CDCl}_{3}, 22{ }^{\circ} \mathrm{C}\right)$ of $3 \boldsymbol{e}$

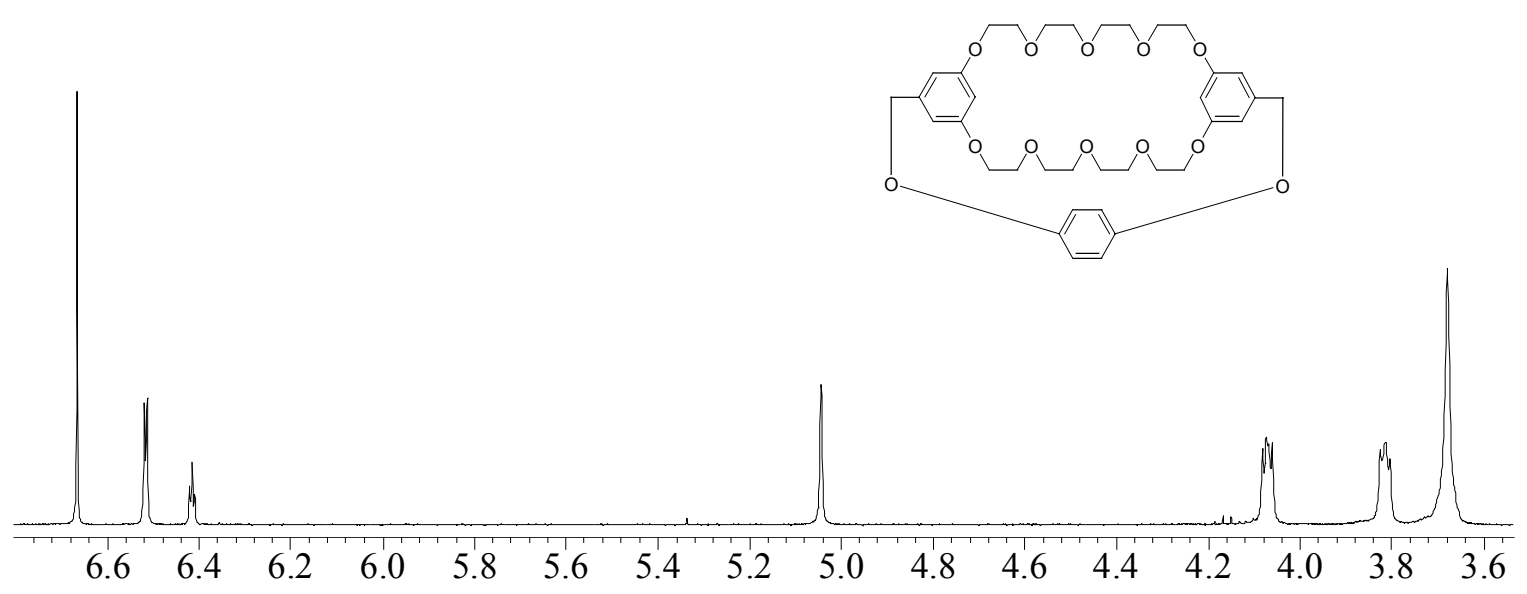

